\title{
Bleeding risks with novel oral anticoagulants especially rivaroxaban versus aspirin: a meta-analysis
}

\author{
Xiehui Chen ${ }^{1 * \dagger}$, Weichao Huang ${ }^{2 \dagger}$, Aimei Sun ${ }^{2}$, Lili Wang ${ }^{2}$, Fanrui $\mathrm{Mo}^{2}$ and Wenqin Guo ${ }^{2^{*}}$ (D)
}

\begin{abstract}
Background: This pairwise meta-analysis determines the difference in bleeding risks associated with the use of novel oral anticoagulants (NOACs) and aspirin.

Methods: PubMed, the Cochrane Library database, clinicaltrial.gov, and related studies were searched for randomized control trials (RCTs) comparing NOAC and aspirin published between January 1, 2000 and May 10, 2021. The primary endpoint was intracranial hemorrhage (ICH).

Results: Eleven studies involving 57,645 patients were included. Compared to aspirin, rivaroxaban (5 mg/day) had a similar risk of $\mathrm{ICH}$, major bleeding, and fatal bleeding; rivaroxaban $(10 \mathrm{mg} /$ day) had higher risks of gastrointestinal hemorrhage (OR: 1.41; 95\% Cl: 1.03-1.94; $P=0.032 ; I^{2}=0 \%$ ) and a similar risk of $\mathrm{ICH}$, major bleeding, and fatal bleeding; and rivaroxaban (15-20 mg/day) had higher risks of ICH (OR: 3.21; 95\% Cl: 1.36-7.60; $P=0.008 ; I^{2}=0 \%$ ), major bleeding (OR: $2.64 ; 95 \% \mathrm{Cl}: 1.68-4.16 ; P<0.001 ; I^{2}=0 \%$ ), and fatal bleeding (OR: $2.26 ; 95 \%$ Cl: $1.25-4.08 ; P=$ $0.007 ; I^{2}=0 \%$ ) and a similar risk of gastrointestinal hemorrhage. Bleeding outcomes between other NOACs (apixaban and dabigatran etexilate) and aspirin were not different.

Conclusions: The bleeding risks associated with NOACs depend on drug type and dosage. For $\geq 15 \mathrm{mg} /$ day of rivaroxaban, the risk of $\mathrm{ICH}$ was significantly higher than that with aspirin. However, further studies comparing dabigatran etexilate and apixaban versus aspirin are warranted to draw a definite conclusion.
\end{abstract}

Keywords: Anticoagulants, Aspirin, Intracranial hemorrhages, Gastrointestinal hemorrhage

\section{Background}

Compared with the traditional anticoagulant warfarin, novel oral anticoagulants (NOACs) have several advantages, including being less affected by food or drugs and not requiring frequent monitoring of the international normalized ratio [1]. The efficacy of NOACs at preventing ischemic strokes is not inferior to that of warfarin, and NOACs are associated with a lower risk of

\footnotetext{
*Correspondence: syxcxh@126.com; guowengin2011@outlook.com

${ }^{+}$Xiehui Chen and Weichao Huang contributed equally to this work.

'Department of Cardiology, Shenzhen Longhua District Central Hospital, No.

187, Guanlan Road, Longhua District, Shenzhen, China

${ }^{2}$ Department of Cardiology, Fuwai Hospital Chinese Academy of Medical

Sciences, No. 12, Langshan Road, Nanshan District, Shenzhen, China
}

intracranial hemorrhage $(\mathrm{ICH})$ than warfarin in patients with high-risk atrial fibrillation (AF) [2]. NOACs are also recommended for the treatment of coronary heart disease (CHD) and venous thromboembolism (VTE) [3, 4].

However, the bleeding profile of NOACs when used in clinical practice remains controversial. The NAVIGATE ESUS, a randomized controlled trial (RCT) evaluating the benefits of rivaroxaban for patients with embolic strokes of undetermined source (ESUS), found that rivaroxaban $(10 \mathrm{mg} /$ day $)$ did not reduce the rate of strokes (ischemic or hemorrhagic) or systemic emboli, but increased the risk of ICH compared to aspirin $(100 \mathrm{mg} /$ day) [5]. The COMPASS study reported that the rate of

C C The Author(s). 2021 Open Access This article is licensed under a Creative Commons Attribution 4.0 International License, which permits use, sharing, adaptation, distribution and reproduction in any medium or format, as long as you give appropriate credit to the original author(s) and the source, provide a link to the Creative Commons licence, and indicate if changes were made. The images or other third party material in this article are included in the article's Creative Commons licence, unless indicated otherwise in a credit line to the material. If material is not included in the article's Creative Commons licence and your intended use is not permitted by statutory regulation or exceeds the permitted use, you will need to obtain permission directly from the copyright holder. To view a copy of this licence, visit http://creativecommons.org/licenses/by/4.0/ The Creative Commons Public Domain Dedication waiver (http://creativecommons.org/publicdomain/zero/1.0/) applies to the data made available in this article, unless otherwise stated in a credit line to the data. 
$\mathrm{ICH}$ and gastrointestinal bleeding in patients administered rivaroxaban $(10 \mathrm{mg} /$ day $)$ was higher than that in patients administered aspirin (100 mg/day) [6]. However, other studies have reported that the bleeding risks of NOACs are similar to those of aspirin [7-9]. Therefore, it is unclear if NOACs are associated with a higher bleeding risk than aspirin. Studies regarding the use of NOACs for other cardiovascular diseases are currently being conducted, including one study comparing the efficacy of NOACs and aspirin for the treatment of patients with $\mathrm{CHD}$ and gastrointestinal diseases undergoing percutaneous coronary intervention [10].

In most of the previously published anticoagulant studies, bleeding was the secondary endpoint, suggesting that the statistical power of these studies was not sufficient to assess the bleeding risk of anticoagulants. A meta-analysis, which can gather all current evidence thereby expanding the sample size and improve the accuracy of estimated outcomes, is a common methodology for the evaluation of a drug's safety profile [11, 12]. This meta-analysis aimed to compare the bleeding risks associated with NOAC use to those of aspirin to guide both clinical practice and research regarding the selection of NOAC type and dosage.

\section{Methods}

This study was conducted according to the Preferred Reporting Items for Systematic Reviews and MetaAnalyses (PRISMA) Statement [13]. PubMed, the Cochrane Library database, clinicaltrial.gov, and the references of related studies were searched by two researchers (Lili Wang and Aimei Sun) for studies published between January 1, 2000 and May 10, 2021. The following keywords and MeSH terms were used: "NOAC," "new oral anticoagulant," "direct oral anticoagulant," "non-vitamin K oral anticoagulant," "rivaroxaban," "dabigatran etexilate," "apixaban," "edoxaban." The research strategies are shown in Supplemental Appendix.

\section{Inclusion and exclusion criteria}

RCTs which had an intervention group that received NOACs (rivaroxaban, dabigatran etexilate, apixaban, or edoxaban) and a control group that received aspirin, which reported one of the clinical outcomes of interest of this study, and which were published in the English language were included in this meta-analysis. Studies in which the intervention group included other anticoagulants (such as warfarin or heparin), the control group was not administered aspirin, the study design was observational or cohort, the outcomes of interest were not reported, or the language of reporting was not English were excluded from this meta-analysis.

\section{Outcomes}

The primary endpoint of this meta-analysis was $\mathrm{ICH}$. The secondary endpoints included fatal bleeding, major bleeding, and gastrointestinal hemorrhage. ICH, fatal bleeding, and gastrointestinal hemorrhage were defined similarly among the included studies, though major bleeding was not. The definitions of the clinical outcomes in the included studies are shown in Supplemental Table 1. The definition of major bleeding in most of the studies was based on the one that is proposed by the International Society on Thrombosis and Haemostasis [14]. The definition of ICH was traumatic and atraumatic intracerebral, subarachnoid, and subdural or epidural hemorrhage (does not include microbleeds or hemorrhagic transformation, does include intraspinal).

\section{Data extraction and study quality assessment}

Two researchers (Weichao Huang and Wenqin Guo) independently extracted the year of publication, mean follow-up time, dosages of the intervention and control groups, total number of events and patients in each group, indications for antithrombotic drugs, and characteristics of the included studies (such as the average age and proportions of stroke, hypertension, and diabetes mellitus). When multiple reports for the same clinical trial were identified, data from the most recent report were used. When the extracted data differed between the two researchers, a third researcher helped us reach a final decision. The intention-to-treat sample size was used for analysis, and the quality of the included studies was assessed by two researchers (Lili Wang and Fanrui Mo) using the Cochrane risk-of-bias tool [15]. If there was a disagreement between the two researchers, the third researcher (Wenqin Guo) made the decision.

\section{Statistical analysis}

The odds ratio (OR) and the corresponding 95\% confidence interval (CI) were used as measures of the effect size. -The random effects model was used for metaanalysis (Mantel-Haenszel method) because the population characteristics were different between the studies [16]. Cochrane $\mathrm{Q}$ tests and the inconsistency index $\left(\mathrm{I}^{2}\right.$ test) were used to assess the statistical heterogeneity among the included studies [17]. An $\mathrm{I}^{2}$ value $<25 \%$ indicated the absence of heterogeneity, an $\mathrm{I}^{2}$ value between 25 and 50\% indicated low heterogeneity, an $\mathrm{I}^{2}$ value between 50 and $75 \%$ indicated moderate heterogeneity, and an $\mathrm{I}^{2}$ value $>75 \%$ indicated high heterogeneity [17]. The funnel plot and Egger's regression asymmetry test were used to assess for publication bias [18]. Subgroup analyses were conducted based on the indications for antithrombotic medications (AF, ESUS, CHE, or VTE); the 12-month incidence of ICH in patients with ischemic stroke is 15 times higher than that in patients without 
ischemic stroke, and AF patients who are not treated with a vitamin $\mathrm{K}$ antagonists are at a higher risk of bleeding $[19,20]$. Statistical significance was set at $P<$ 0.05 . The meta-analysis was conducted using STATA Software Version 12.0, (StataCorp, University City, Texas, USA) and Review Manager Software (version 5.4, The Cochrane Collaboration, Copenhagen, Denmark).

\section{Results}

During screening, abstracts of 1830 studies were read (Fig. 1). Eleven studies reporting 10 RCTs involving 57,645 patients were included in this analysis $[5-9,21-$ 26]. A study conducted by Anand et al. [27] was excluded as it included patients with stable peripheral or carotid artery disease whose data were included in the study by Eikelboom et al. [6]. The GALILEO study [28] and the ePAD trial [29] were excluded because some or all of the control groups received clopidogrel. A study by Zou et al. included three treatment arms (aspirin, lowmolecular-weight heparin, and rivaroxaban). Data from the aspirin and rivaroxaban groups were included in this meta-analysis [21]. The COMPASS trial compared the effectiveness of aspirin (100 mg/day), rivaroxaban (10 $\mathrm{mg} /$ day.), and aspirin ( $100 \mathrm{mg} /$ day) plus rivaroxaban (5 $\mathrm{mg} /$ day) [6]. The comparison between aspirin $(100 \mathrm{mg} /$ day) and rivaroxaban $(10 \mathrm{mg} /$ day $)$ was included in the meta-analysis. Table 1 summarizes the characteristics of included studies. The daily dosage of aspirin was $100 \mathrm{mg}$ in six studies [5-8, 21, 23], $81 \mathrm{mg}$ daily in two studies [25, 26], $200 \mathrm{mg}$ in one study [22], and $81-324 \mathrm{mg}$ in one study [9]. The included studies had follow-up periods ranging from 1 to 23 months. The quality of the studies is reported in Fig. 2. Overall, the risk of bias in the included studies was low.

\section{Clinical outcomes \\ Intracranial hemorrhage}

One study evaluated the ICH risks associated with a $5 \mathrm{mg} /$ day rivaroxaban regimen, four evaluated the $\mathrm{ICH}$ risks associated with a $10 \mathrm{mg} /$ day rivaroxaban regimen, two evaluated the $\mathrm{ICH}$ risks associated with a $15-20 \mathrm{mg} /$ day rivaroxaban regimen, one evaluated the $\mathrm{ICH}$ risks associated with the administration of dabigatran etexilate, and one study evaluated the $\mathrm{ICH}$ risks associated with the use of apixaban (Fig. 3). The ICH risks associated with apixaban (OR: 0.84; 95\% CI: 0.38-1.88; $P=0.672$ ), dabigatran etexilate (OR: 1.00 ; 95\% CI: $0.61-1.64 ; P=1.000$ ), $5 \mathrm{mg}$ / day rivaroxaban (OR: 3.00 ; 95\% CI: $0.12-73.70 ; P=0.501$ ), and $10 \mathrm{mg}$ /day rivaroxaban regimen (OR: 1.67; 95\% CI: $\left.0.91-3.04 ; P=0.097 ; \mathrm{I}^{2}=4.3 \%\right)$ were similar to those

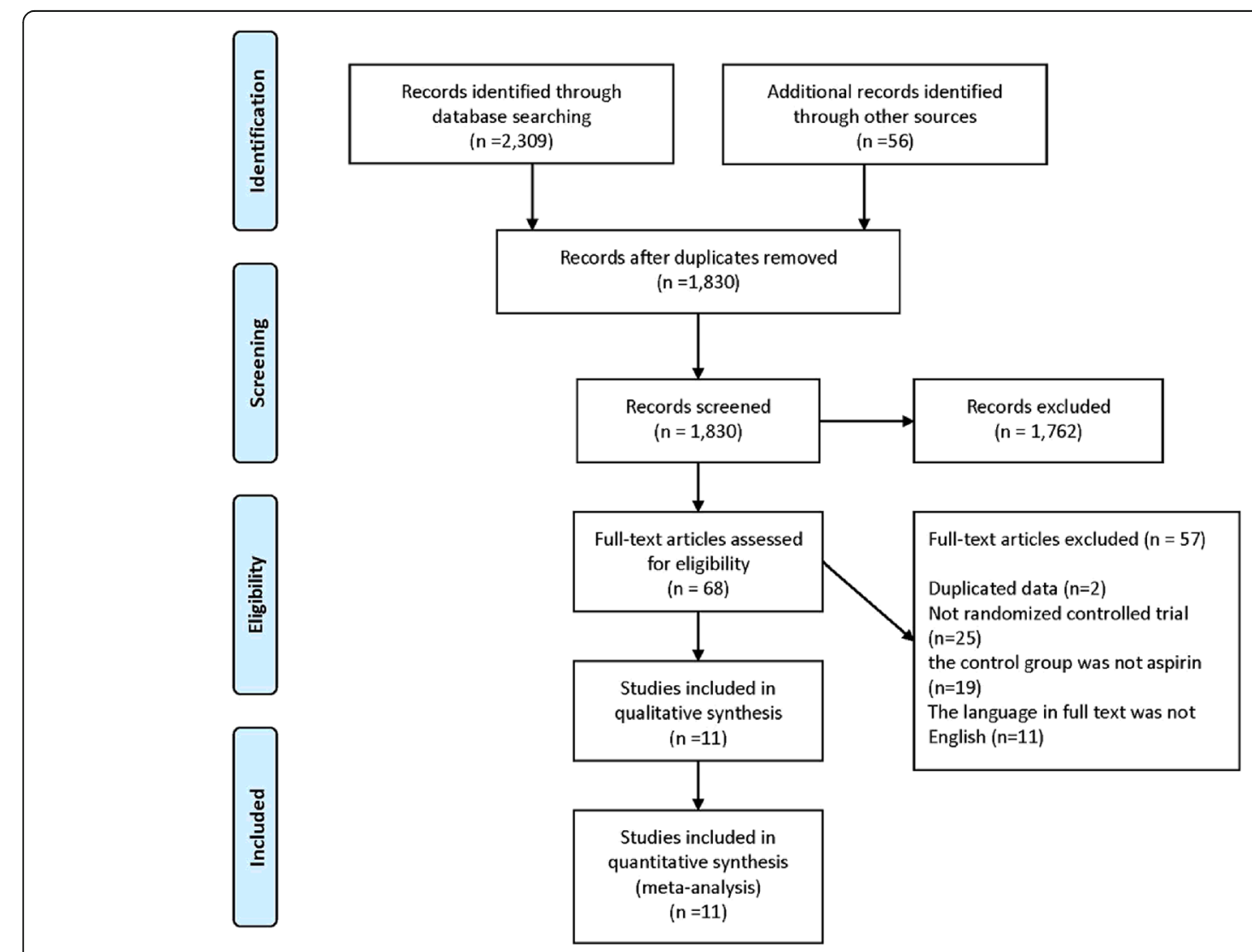

Fig. 1 The flow chart of literature search and selection 


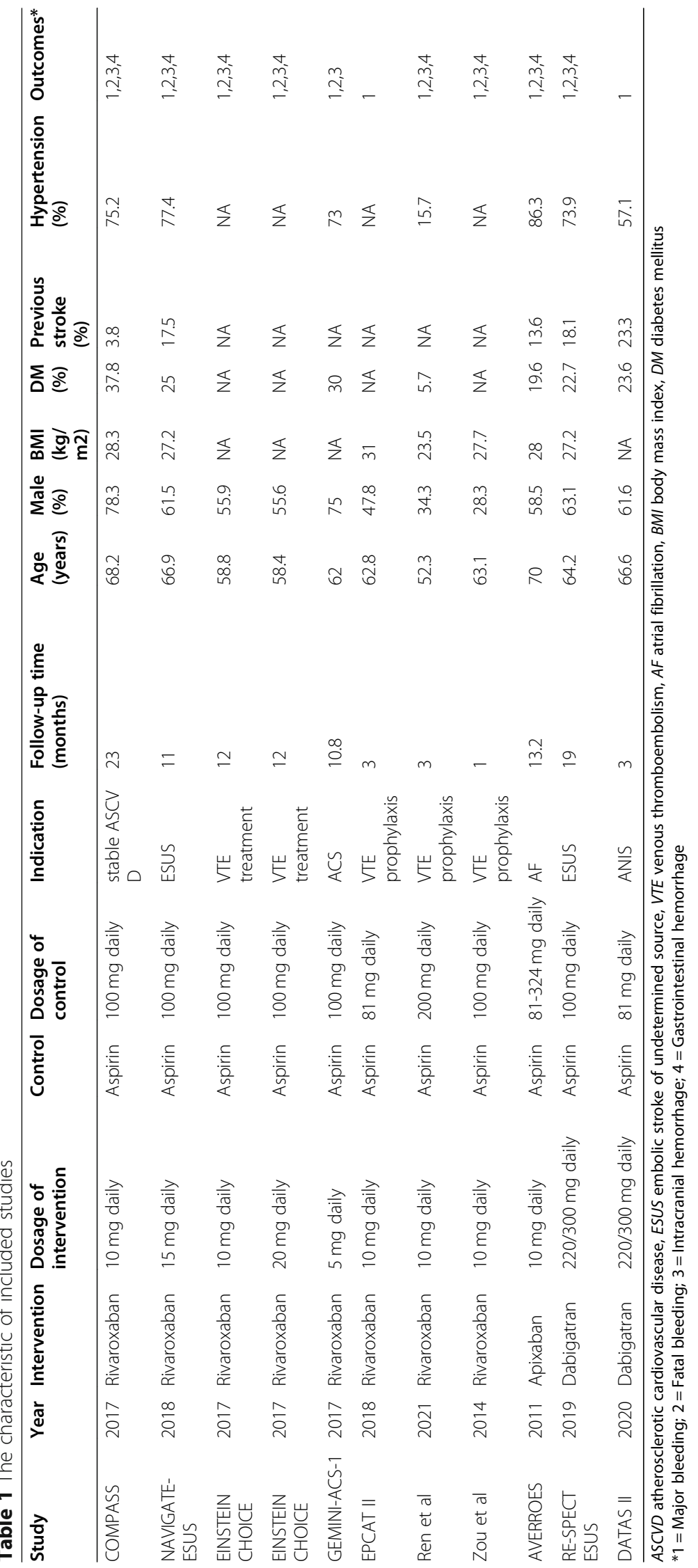




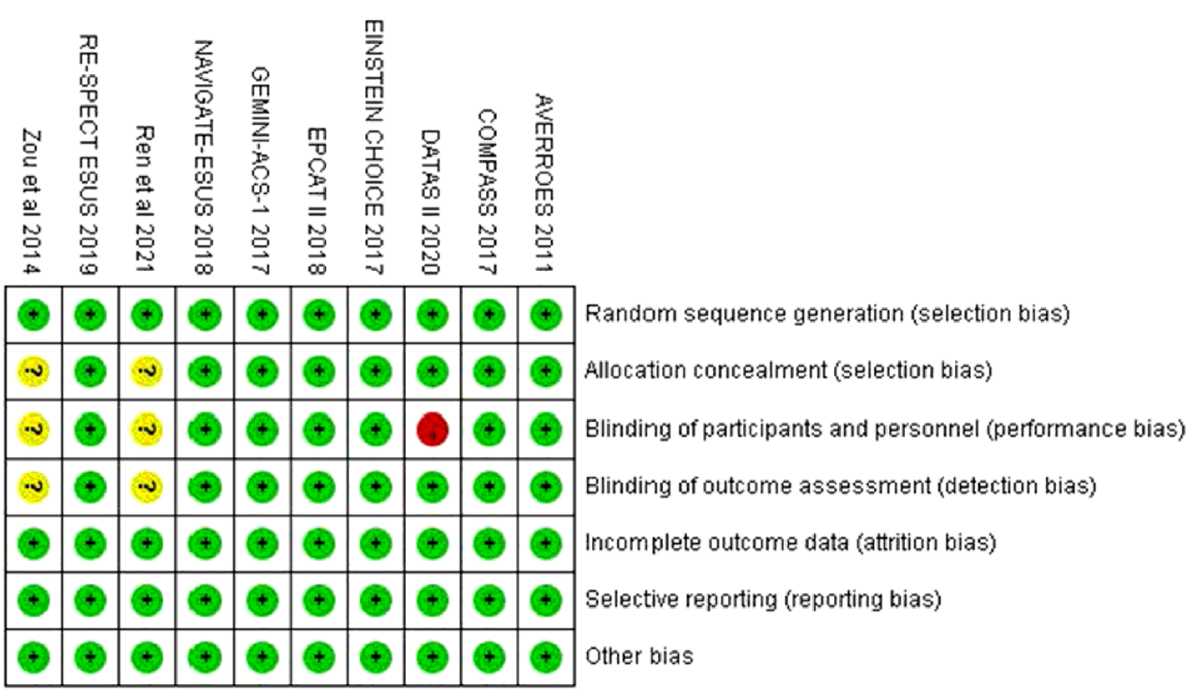

Fig. 2 The assessment of Cochrane risk-of-bias

associated with aspirin. The ICH risks associated with 15$20 \mathrm{mg} /$ day rivaroxaban regimen (OR: 3.21; 95\% CI: $1.36-$ $7.60 ; P=0.008 ; \mathrm{I}^{2}=0 \%$ ) were significantly higher than those associated with aspirin use.

\section{Major bleeding}

The major bleeding risks were evaluated by one study for $5 \mathrm{mg} /$ day rivaroxaban, five studies for $10 \mathrm{mg}$ /day rivaroxaban, two studies for $15-20 \mathrm{mg} /$ day rivaroxaban, one study for dabigatran etexilate, and one study for the administration of apixaban (Fig. 4). The major bleeding risks associated with the administration of apixaban (OR: $1.12 ; 95 \%$ CI: $0.73-1.73 ; P=0.600$ ), dabigatran etexilate (OR: 1.21 ; $95 \%$ CI: $0.86-1.69 ; P=0.268$ ), $5 \mathrm{mg} /$ day rivaroxaban (OR: 1.25 ; 95\% CI: $0.49-3.18 ; P=0.638)$, and $10 \mathrm{mg} /$ day rivaroxaban (OR: 1.38 ; $95 \% \mathrm{CI}: 0.92-$

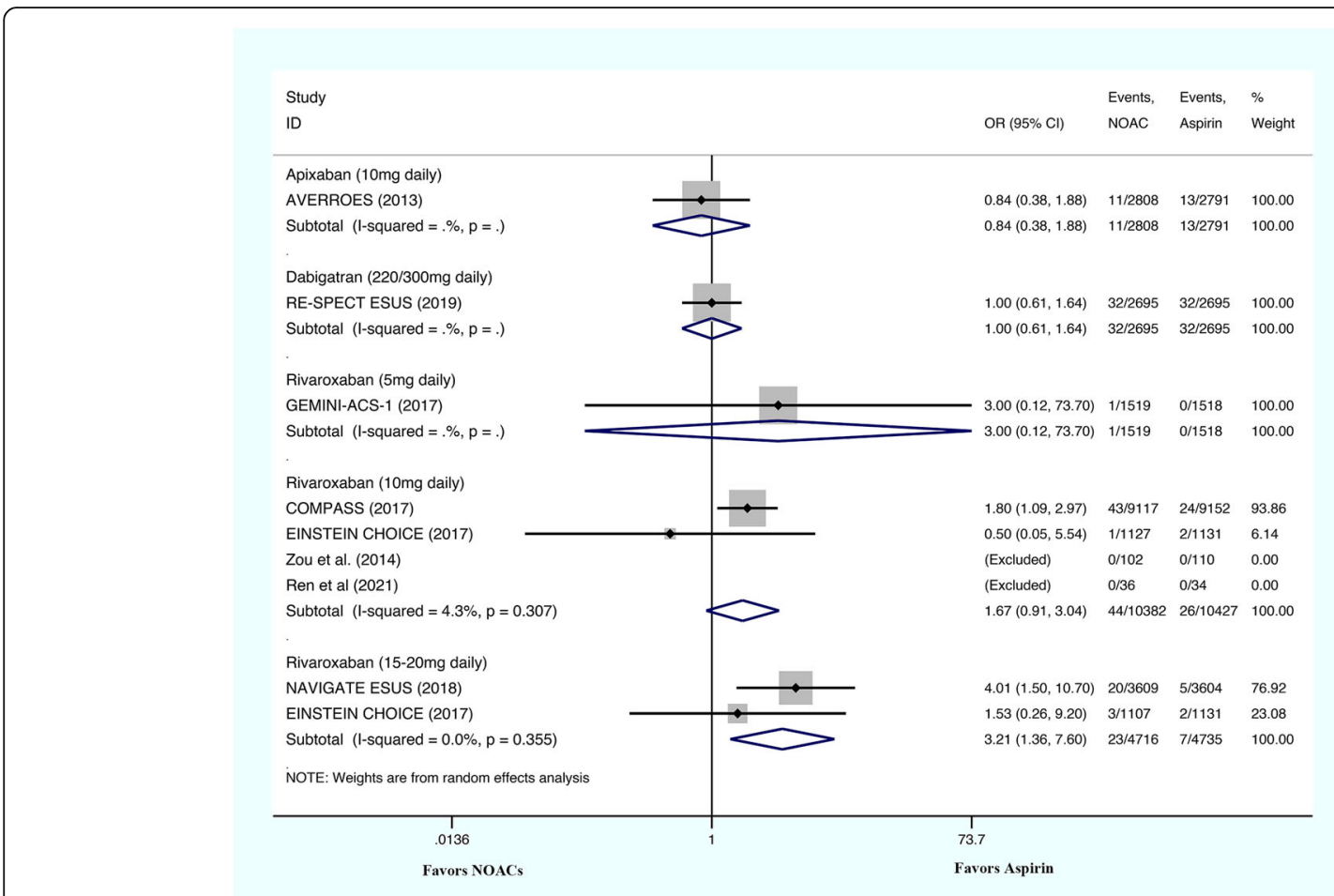

Fig. 3 The results of meta-analysis regarding the outcome of intracranial hemorrhage 


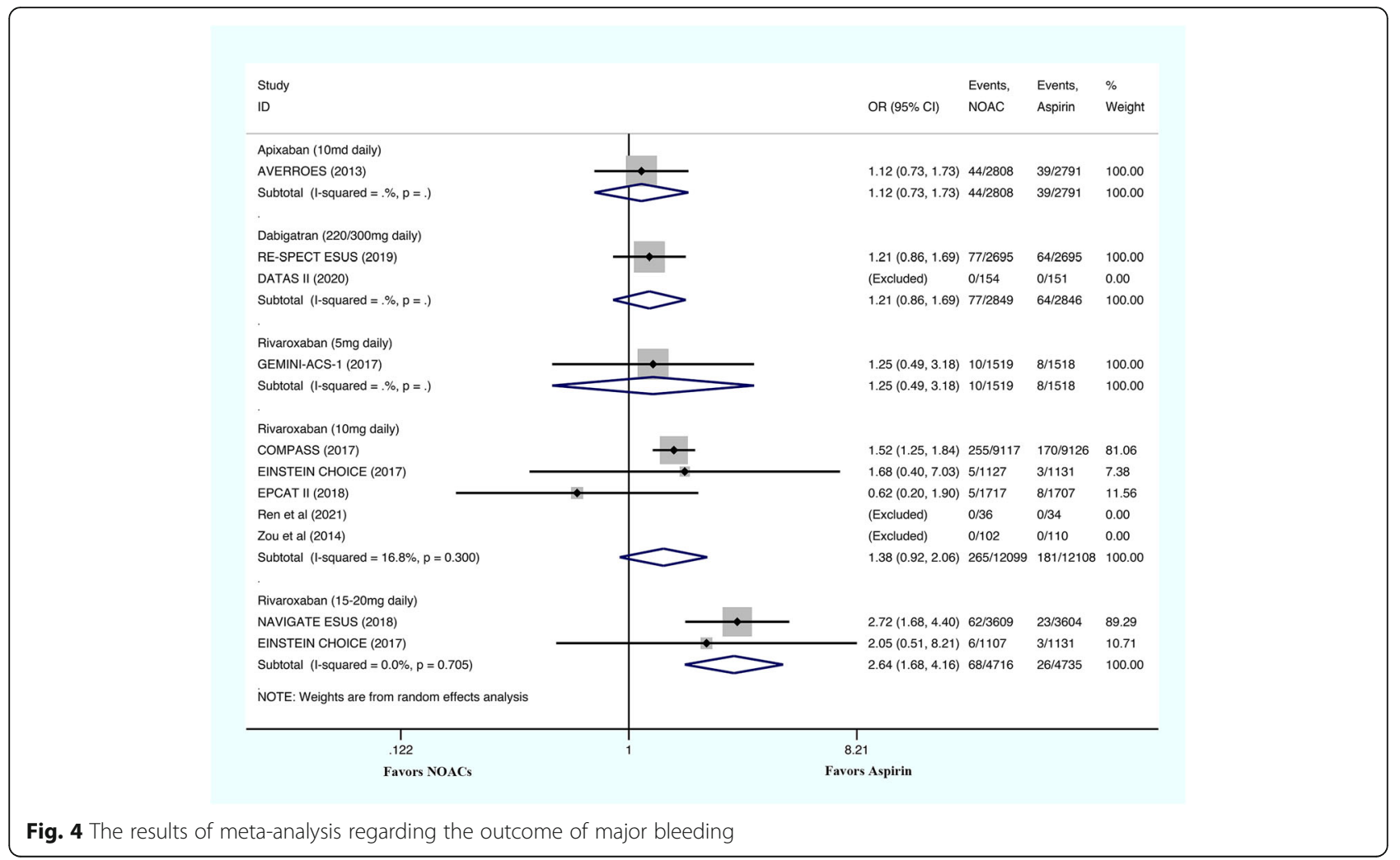

2.06; $\left.P=0.121 ; \mathrm{I}^{2}=16.8 \%\right)$ were similar to those associated with aspirin. The risk of major bleeding was significantly higher in patients who received $15-20 \mathrm{mg}$ of rivaroxaban daily (OR: 2.64; 95\% CI: $1.68-4.16 ; P<$ $\left.0.001 ; \mathrm{I}^{2}=0 \%\right)$.

\section{Fatal bleeding}

The fatal bleeding risks were evaluated by one study for $5 \mathrm{mg} /$ day rivaroxaban, four studies for $10 \mathrm{mg} /$ day rivaroxaban, two studies for $15-20 \mathrm{mg} /$ day rivaroxaban, one study for administration of dabigatran etexilate, and one study for the use of apixaban (Fig. 5). The fatal bleeding risks associated with apixaban (OR: 0.66; 95\% CI: 0.192.35; $P=0.523$ ), dabigatran etexilate (OR: $0.17 ; 95 \% \mathrm{CI}$ : $0.02-1.38 ; P=0.097$ ), $5 \mathrm{mg} /$ day rivaroxaban (OR: 5.00; 95\% CI: $0.24-104.30 ; P=0.299)$, and $10 \mathrm{mg} /$ day rivaroxaban (OR: $1.29 ; 95 \%$ CI: 0.59-2.82; $P=0.532 ; \mathrm{I}^{2}=0 \%$ ) were similar to those of aspirin, while the fatal bleeding risks associated with $15-20 \mathrm{mg}$ /day rivaroxaban regimen were significantly higher than those associated with aspirin (OR: 2.26; 95\% CI: $1.25-4.08 ; P=0.007$; $\mathrm{I}^{2}=0 \%$ ).

\section{Gastrointestinal hemorrhage}

The risks for gastrointestinal hemorrhage were evaluated by four studies for $10 \mathrm{mg} /$ day rivaroxaban, two studies for $15-20 \mathrm{mg} /$ day rivaroxaban, one study for the administration of dabigatran etexilate, and one study for use of apixaban (Fig. 6). The risks of gastrointestinal hemorrhage associated with 15-20 mg/day rivaroxaban (OR: 1.84; 95\% CI: $\left.0.91-3.72 ; P=0.091 ; \mathrm{I}^{2}=0 \%\right)$, dabigatran etexilate (OR: $1.23 ; 95 \% \mathrm{CI}: 0.70-2.16 ; P=0.474$ ), and apixaban (OR: 0.85 ; $95 \%$ CI: $0.39-1.84 ; P=0.683$ ) were similar to those associated with aspirin. The gastrointestinal hemorrhage risks associated with a $10 \mathrm{mg}$ /day rivaroxaban regimen were significantly higher than those associated with aspirin use (OR: $1.41 ; 95 \% \mathrm{CI}$ : $1.03-1.94 ; P=0.032$; $\left.\mathrm{I}^{2}=0 \%\right)$.

\section{Additional analysis}

The subgroup analysis is showed in Fig.7. The $\mathrm{ICH}$ risk was similar between AF patients who received $10 \mathrm{mg} /$ day apixaban and those who received aspirin. A 15-20 $\mathrm{mg} /$ day dose of rivaroxaban was associated with a significantly higher risk of ICH than aspirin (OR: 4.01; 95\% CI: $1.50-10.70 ; P=0.006)$ in patients with ESUS. Dabigatran $(220 / 300 \mathrm{mg} /$ day $)$ was not associated with an increased risk of $\mathrm{ICH}$ compared to aspirin. In patients with CHD or VTE, doses of $5 \mathrm{mg} /$ day, $10 \mathrm{mg} /$ day, and 15-20 mg/day of rivaroxaban were not associated with an increased risk of ICH in patients with CHD or VTE.

The publication bias was not assessed because the number of included studies in every comparison was less than ten.

\section{Discussion}

In this study, the risks of $\mathrm{ICH}$, major bleeding, and fatal bleeding were higher in patients receiving doses $\geq 15 \mathrm{mg} /$ 


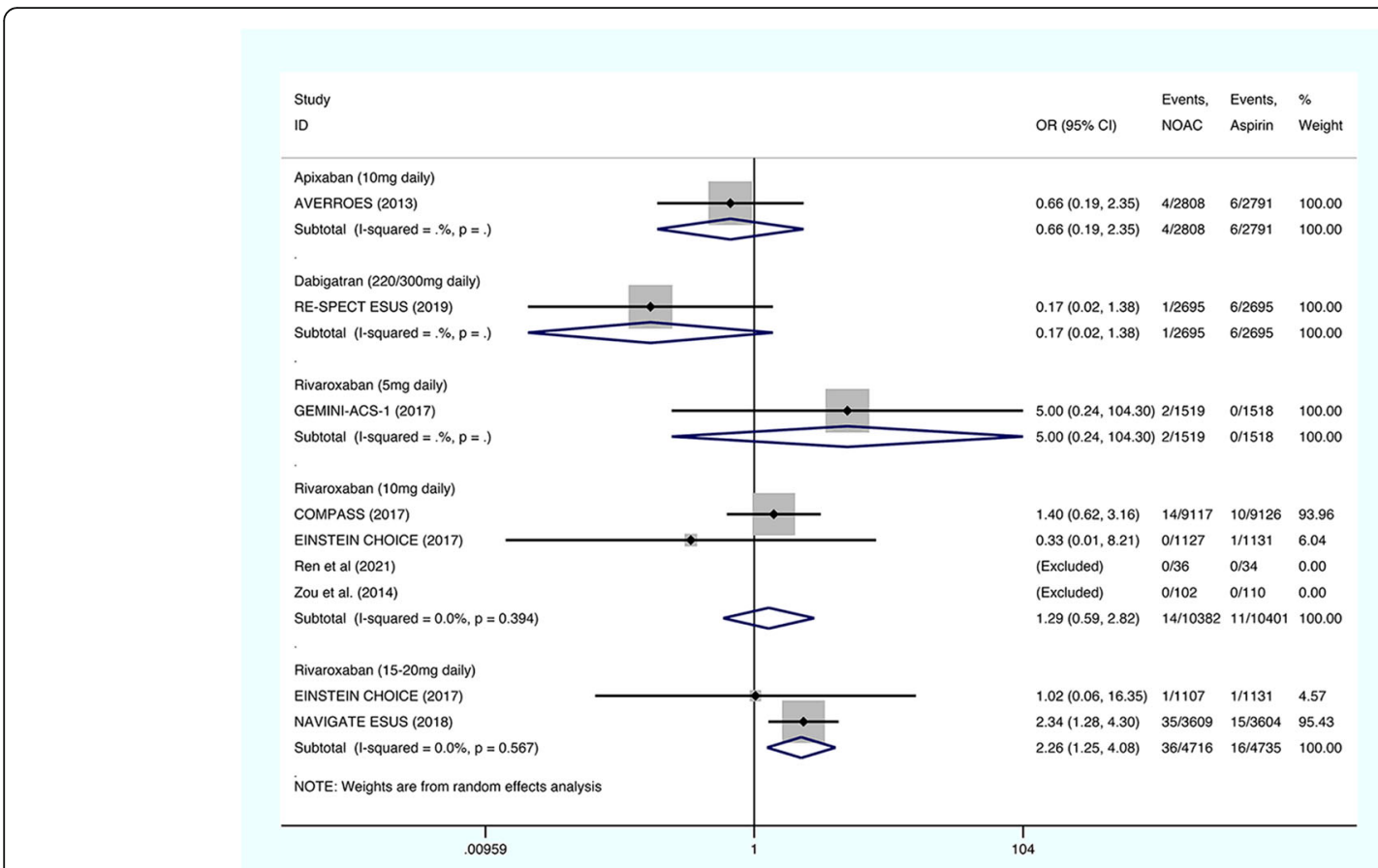

Fig. 5 The results of meta-analysis regarding the outcome of fatal bleeding

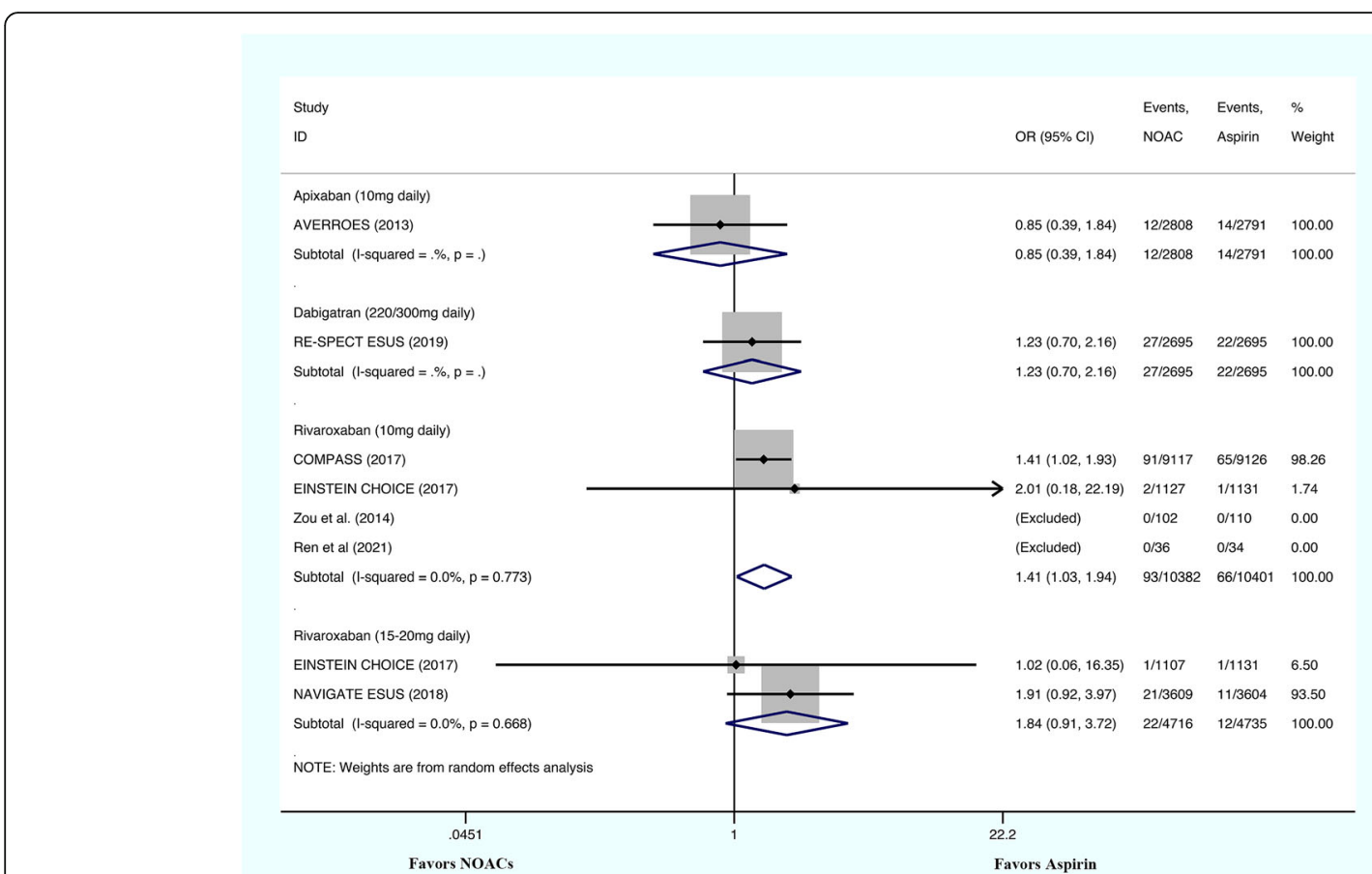

Fig. $\mathbf{6}$ The results of meta-analysis regarding the outcome of gastrointestinal hemorrhage 


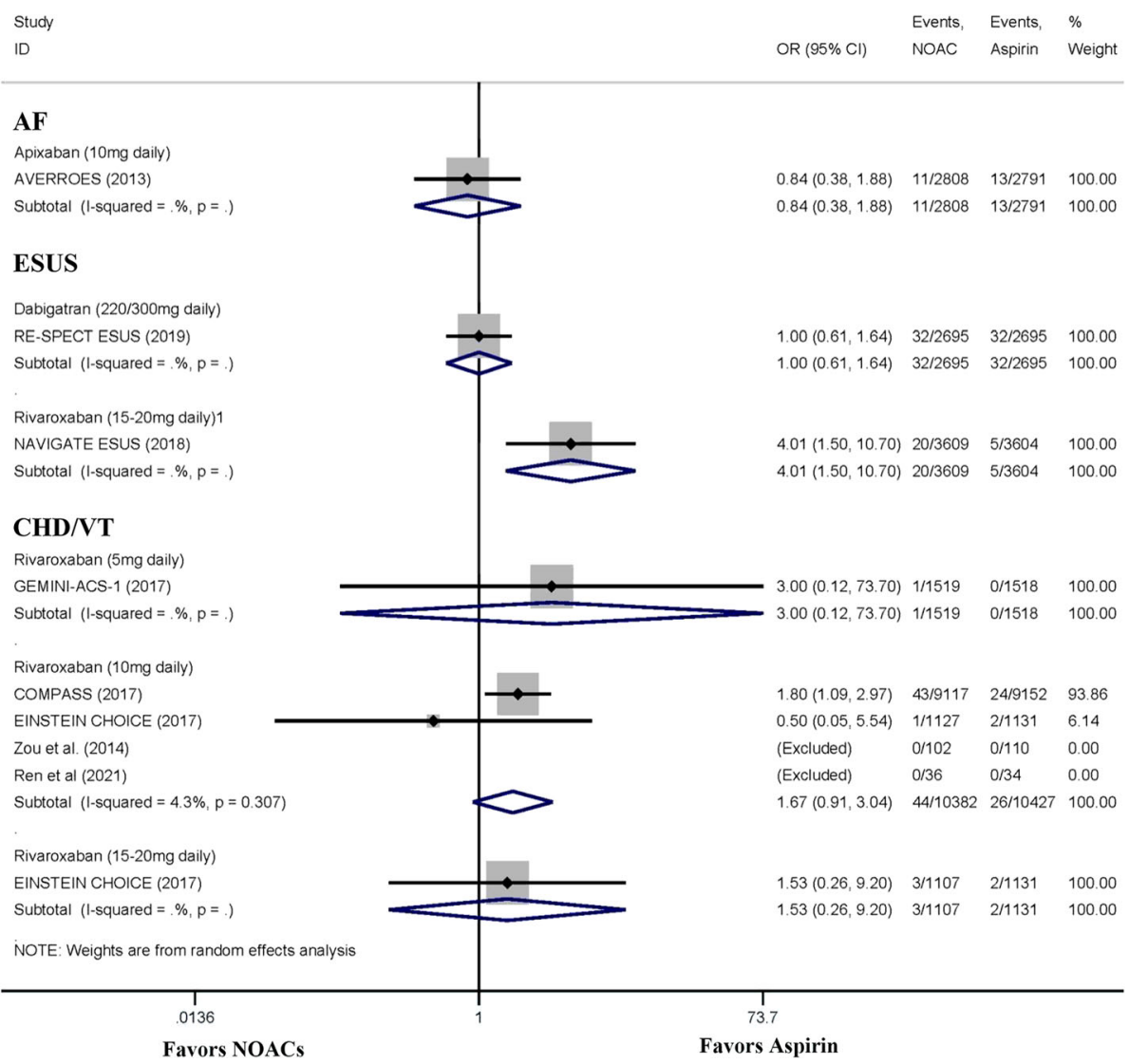

Fig. 7 The subgroup analysis of the meta-analysis base on the indication

day rivaroxaban than in those receiving aspirin, while patients receiving $\leq 10 \mathrm{mg} /$ day rivaroxaban did not show higher risks. The dose of $10 \mathrm{mg} /$ day rivaroxaban was associated with higher risks of gastrointestinal hemorrhage than that of aspirin. The risks of fatal bleeding, major bleeding, and intracranial and gastrointestinal hemorrhage associated with dabigatran etexilate and apixaban were similar to those for aspirin.

Huang et al. conducted a meta-analysis comparing the $\mathrm{ICH}$ risk associated with NOACs and aspirin that included five RCTs and 39,398 patients [30]. The results of the previous meta-analysis suggested that the risk of $\mathrm{ICH}$ associated with rivaroxaban use was dose-related. The risk of $\mathrm{ICH}$ associated with $>15 \mathrm{mg} /$ day rivaroxaban was significantly higher than that of aspirin. The current meta-analysis is an updated study that incorporates studies published after 2018 and has multiple endpoints. The results of this meta-analysis suggest that $\geq 15 \mathrm{mg} /$ day of rivaroxaban not only increased the risks of $\mathrm{ICH}$ but also increased major and fatal bleeding compared with aspirin. Sagris et al. performed a regression metaanalysis comparing the bleeding risks between NOACs and aspirin used for the treatment of AF [31]. The previous meta-analysis included four studies and found that the risk of $\mathrm{ICH}$ and gastrointestinal bleeding due to NOACs was similar to that of aspirin. Therefore, the study does not support replacing NOACs with aspirin as an antithrombotic for patients with $\mathrm{AF}$ and high bleeding risks. However, the previous study merged results from studies regarding different types of NOACs, which may have masked the effects of rivaroxaban regarding $\mathrm{ICH}$.

A previous study reported that the ICH risk associated with the use of NOACs is significantly lower than that associated with the use of warfarin [2]. The American Heart Association/American College of Cardiology and European Society of Cardiology guidelines recommend NOACs as the preferred anticoagulant for patients with high-risk AF (CHA2DS2-VASc score $\geq 3$ in women or $\geq$ 2 in men) [32,33]. The effectiveness of NOACs for VTE and chronic coronary syndrome has been confirmed in previous studies $[6,8]$. However, there is a risk of bleeding when NOACs are used. The NAVIGATE ESUS study that assessed the effectiveness of rivaroxaban for patients with ESUS showed that ICH risks with $15 \mathrm{mg} /$ day of rivaroxaban were significantly higher than those of $100 \mathrm{mg} /$ day of aspirin (HR: 4.02; 95\% CI:1.51-10.7) [5]. The GALILEO study, which evaluated the benefits 
of rivaroxaban for preventing thromboembolic events after transcatheter aortic valve replacement (TAVR) [28], involved the administration of $10 \mathrm{mg} /$ day rivaroxaban or an antiplatelet agent (aspirin or clopidogrel) to patients after TAVR; it found that patients receiving rivaroxaban had a significantly higher risk of bleeding than those receiving antiplatelet monotherapy. The COMPASS study evaluated the effectiveness of rivaroxaban in patients with stable atherosclerotic vascular disease and compared the effects of $100 \mathrm{mg} /$ day of aspirin, $10 \mathrm{mg} /$ day of rivaroxaban, and $5 \mathrm{mg} /$ day of rivaroxaban plus $100 \mathrm{mg} /$ day of aspirin; it was found that $10 \mathrm{mg} /$ day of rivaroxaban was associated with a higher risk of $\mathrm{ICH}$ than $100 \mathrm{mg} /$ day of aspirin [6]. The GEMINI-ACS-1 study, which assessed the safety profile of rivaroxaban in patients with acute coronary syndrome [23], found that the bleeding risk associated with the use of $5 \mathrm{mg} /$ day of rivaroxaban was similar to that of $100 \mathrm{mg} /$ day of aspirin when all patients also received a P2Y12 inhibitor. The RE-SPECT ESUS study, another RCT that evaluated the clinical benefits of dabigatran etexilate for the treatment of ESUS, demonstrated that the bleeding risks of dabigatran etexilate and aspirin were similar [7]. The AVERROES study evaluated the effectiveness and safety of apixaban for the prevention of stroke in high-risk patients with AF [9]. The study randomly divided patients who could not tolerate warfarin into groups, i.e., patients who received $10 \mathrm{mg} /$ day rivaroxaban or $81-324 \mathrm{mg} /$ day aspirin. The results showed that the bleeding risks were not significantly different between the groups. Therefore, the bleeding risks associated with the use of NOACs are related to the dosage and drug type. The results of this meta-analysis confirmed this hypothesis. As ICH and gastrointestinal hemorrhage were not the primary endpoints of the previous study, there was limited statistical power to evaluate these events. In this study, a rivaroxaban dose $\geq 15 \mathrm{mg}$ was associated with a higher risk of $\mathrm{ICH}$, fatal bleeding, and major bleeding. The risk of gastrointestinal bleeding associated with $15-20 \mathrm{mg} /$ day rivaroxaban was similar to the risk associated with aspirin, which may be attributed to the small sample size of the included studies. Previous studies on high-dose rivaroxaban did not report the incidence of gastrointestinal hemorrhage in detail and were not included in the meta-analysis of gastrointestinal hemorrhage; this may have led to an underestimation of the risk of gastrointestinal hemorrhage associated with higher doses of rivaroxaban. Although the results found that the bleeding risk of dabigatran and apixaban was not different from that of aspirin, the number of included studies was small; therefore, the statistical power was low. Future studies comparing the dabigatran etexilate and apixaban versus aspirin are warranted to draw an exact conclusion.
As the net clinical benefits of NOACs are superior to those of warfarin, the indications for NOACs have been extended to include various cardiovascular diseases $[1,6$, 8]. Antiplatelet therapy is the cornerstone of treatment for secondary prevention of atherosclerosis [34]. However, the results of the COMPASS study confirmed that low-dose rivaroxaban combined with aspirin further reduce the risk of cardiac death compared with aspirin alone in patients with stable atherosclerotic vascular disease [6]. Therefore, low-dose rivaroxaban is approved for the treatment of chronic coronary syndrome [3]. The GEMINI-ACS-1 study showed that low-dose rivaroxaban combined with P2Y12 inhibitors could replace the traditional dual antiplatelet regimen administered to patients with acute coronary syndrome [23]. More RCTs are needed to compare the efficacy of NOACs and antiplatelet drugs for the treatment of cardiovascular diseases including acute coronary syndrome. Therefore, this study will serve as a reference for dosage selection in the design of future studies. Also, as some patients with indications for NOACs may be at high risk for ischemia or bleeding, an optimal antithrombotic regimen is important. The results of this study can help physicians make optimal clinical decisions for these patients.

\section{Limitations}

This study had some limitations. First, the meta-analysis included few studies and regression analysis to evaluate the association between population characteristics and clinical outcomes could not be conducted. Second, the bleeding risks between the NOAC and P2Y12 inhibitors (clopidogrel or ticagrelor) could not be compared as there were very few direct comparisons of the efficacy and safety of these agents. Third, the definition of major bleeding was inconsistent between the included studies; however, most of the studies used the International Society on Thrombosis and Haemostasis definition of major bleeding. As the definition of $\mathrm{ICH}$ was relatively consistent among the included studies, ICH was set as the primary endpoint of this study. Fourth, although the bleeding risk between the various doses of rivaroxaban was different, the studies included in this analysis were quite heterogeneous with different indications, study populations and co-medications. Therefore, the results of this meta-analysis should be interpreted with caution.

\section{Conclusion}

In conclusion, the risks of bleeding associated with the use of NOACs were related to the type and dose of the drug. The risks of $\mathrm{ICH}$ associated with $\geq 15 \mathrm{mg} /$ day rivaroxaban were significantly higher than those of aspirin. However, future studies comparing dabigatran etexilate and apixaban versus aspirin are warranted to draw a more informed conclusion. 


\section{Abbreviations}

AF: Atrial fibrillation; CHD: Coronary heart disease; ESUS: Embolic stroke of undetermined source; HR: Hazard ratio; ICH: Intracranial hemorrhage; NOAC: Novel oral anticoagulant; OR: Odds ratio; RCT: Randomized controlled trial; VTE: Venous thromboembolism

\section{Supplementary Information}

The online version contains supplementary material available at https://doi. org/10.1186/s12959-021-00322-6.

\section{Additional file 1.}

\section{Acknowledgements}

Not applicable.

\section{Authors' contributions}

XC and WH conceived and designed this meta-analysis. LW and AS conducted literature searchess. WG and FM analyzed data. XC, WH and WG wrote the manuscript. All authors have approved the final manuscript as submitted.

\section{Funding}

This study was supported by Shenzhen Science and Technology Research Funding 20170502165510880; JCYJ20180302173854598.

\section{Availability of data and materials}

Data and statistical analysis are available upon request to corresponding author.

\section{Declarations}

Ethics approval and consent to participate Not applicable.

\section{Consent for publication}

All authors have consented for the publication.

\section{Competing interests}

The authors declare that they have no competing interests.

Received: 7 June 2021 Accepted: 19 September 2021

Published online: 02 October 2021

\section{References}

1. Yeh $\mathrm{CH}$, Hogg $\mathrm{K}$, Weitz Jl. Overview of the new oral anticoagulants: opportunities and challenges. Arterioscler Thromb Vasc Biol. 2015;35(5): 1056-65.

2. Ruff CT, Giugliano RP, Braunwald E, Hoffman EB, Deenadayalu N, Ezekowitz $M D$, et al. Comparison of the efficacy and safety of new oral anticoagulants with warfarin in patients with atrial fibrillation: a meta-analysis of randomised trials. Lancet. 2014:383(9921):955-62.

3. Knuuti J, Wijns W, Saraste A, Capodanno D, Barbato E, Funck-Brentano C, et al. 2019 ESC guidelines for the diagnosis and management of chronic coronary syndromes. Eur Heart J. 2020;41(3):407-77.

4. Ortel TL, Neumann I, Ageno W, Beyth R, Clark NP, Cuker A, et al. American Society of Hematology 2020 guidelines for management of venous thromboembolism: treatment of deep vein thrombosis and pulmonary embolism. Blood Adv. 2020;4(19):4693-738.

5. Hart RG, Sharma M, Mundl H, Kasner SE, Bangdiwala SI, Berkowitz SD, et al Rivaroxaban for stroke prevention after embolic stroke of undetermined source. N Engl J Med. 2018;378(23):2191-201.

6. Eikelboom JW, Connolly SJ, Bosch J, Dagenais GR, Hart RG, Shestakovska O, et al. Rivaroxaban with or without aspirin in stable cardiovascular disease. N Engl J Med. 2017;377(14):1319-30

7. Diener HC, Sacco RL, Easton JD, Granger CB, Bernstein RA, Uchiyama S, et al. Dabigatran for prevention of stroke after embolic stroke of undetermined source. N Engl J Med. 2019;380(20):1906-17.
8. Weitz Jl, Lensing AWA, Prins MH, Bauersachs R, Beyer-Westendorf J, Bounameaux $\mathrm{H}$, et al. Rivaroxaban or aspirin for extended treatment of venous thromboembolism. N Engl J Med. 2017;376(13):1211-22.

9. Connolly SJ, Eikelboom J, Joyner C, Diener HC, Hart R, Golitsyn S, et al. Apixaban in patients with atrial fibrillation. N Engl J Med. 2011;364(9):80617.

10. Rivaroxaban or Aspirin in Patients With CHD \& GD Undergoing PCl. https:// clinicaltrials.gov/ct2/show/NCT04805710. Access at May 20.

11. Stoto MA. Drug safety meta-analysis: promises and pitfalls. Drug Saf. 2015; 38(3):233-43.

12. DerSimonian R, Laird N. Meta-analysis in clinical trials. Control Clin Trials. 1986;7(3):177-88.

13. Liberati A, Altman DG, Tetzlaff J, Mulrow C, Gotzsche PC, loannidis JP, et al. The PRISMA statement for reporting systematic reviews and meta-analyses of studies that evaluate healthcare interventions: explanation and elaboration. BMJ. 2009;339:b2700

14. Schulman S, Kearon C. Subcommittee on control of anticoagulation of the S, standardization Committee of the International Society on T, Haemostasis: definition of major bleeding in clinical investigations of antihemostatic medicinal products in non-surgical patients. J Thromb Haemost. 2005;3(4): $692-4$.

15. Higgins JP, Altman DG, Gotzsche PC, Juni P, Moher D, Oxman AD, et al. The Cochrane Collaboration's tool for assessing risk of bias in randomised trials. Bmj. 2011;343:d5928.

16. Mantel N, Haenszel W. Statistical aspects of the analysis of data from retrospective studies of disease. J Natl Cancer Inst. 1959;22(4):719-48.

17. Higgins JP, Thompson SG, Deeks JJ, Altman DG. Measuring inconsistency in meta-analyses. BMJ. 2003;327(7414):557-60.

18. Egger M, Davey Smith G, Schneider M, Minder C. Bias in meta-analysis detected by a simple, graphical test. BMJ. 1997;315(7109):629-34.

19. Ogren J, Irewall AL, Bergstrom L, Mooe T. Intracranial hemorrhage after ischemic stroke: incidence, time trends, and predictors in a Swedish Nationwide cohort of 196765 patients. Circ Cardiovasc Qual Outcomes. 2015:8(4):413-20.

20. Lopes LC, Spencer FA, Neumann I, Ventresca M, Ebrahim S, Zhou Q, et al. Systematic review of observational studies assessing bleeding risk in patients with atrial fibrillation not using anticoagulants. PLoS One. 2014;9(2): e88131.

21. Zou Y, Tian S, Wang Y, Sun K. Administering aspirin, rivaroxaban and lowmolecular-weight heparin to prevent deep venous thrombosis after total knee arthroplasty. Blood Coagul Fibrinolysis. 2014;25(7):660-4.

22. Ren Y, Cao SL, Li Z, Luo T, Feng B, Weng XS. Comparable efficacy of 100 mg aspirin twice daily and rivaroxaban for venous thromboembolism prophylaxis following primary total hip arthroplasty: a randomized controlled trial. Chin Med J. 2021:134(2):164-72.

23. Ohman EM, Roe MT, Steg PG, James SK, Povsic TJ, White J, et al. Clinically significant bleeding with low-dose rivaroxaban versus aspirin, in addition to P2Y12 inhibition, in acute coronary syndromes (GEMINIACS-1): a double-blind, multicentre, randomised trial. Lancet. 2017; 389(10081):1799-808.

24. Mikulik R, Eckstein J, Pearce LA, Mundl H, Rudilosso S, Olavarria W, et al. Frequency and predictors of major bleeding in patients with embolic strokes of undetermined source: NAVIGATE-ESUS trial. Stroke. 2020;51(7): 2139-47.

25. Butcher KS, Ng K, Sheridan P, Field TS, Coutts SB, Siddiqui M, et al. Dabigatran treatment of acute Noncardioembolic ischemic stroke. Stroke. 2020;51(4):1190-8.

26. Anderson DR, Dunbar M, Murnaghan J, Kahn SR, Gross P, Forsythe M, et al Aspirin or rivaroxaban for VTE prophylaxis after hip or knee arthroplasty. $N$ Engl J Med. 2018;378(8):699-707.

27. Anand SS, Bosch J, Eikelboom JW, Connolly SJ, Diaz R, Widimsky P, et al. Rivaroxaban with or without aspirin in patients with stable peripheral or carotid artery disease: an international, randomised, double-blind, placebocontrolled trial. Lancet. 2018:391(10117):219-29.

28. Dangas GD, Tijssen JGP, Wohrle J, Sondergaard L, Gilard M, Mollmann H, et al. A controlled trial of rivaroxaban after Transcatheter aortic-valve replacement. N Engl J Med. 2020;382(2):120-9.

29. Moll F, Baumgartner I, Jaff M, Nwachuku C, Tangelder M, Ansel G, et al. Edoxaban plus aspirin vs dual antiplatelet therapy in endovascular treatment of patients with peripheral artery disease: results of the ePAD trial. J Endovasc Ther. 2018;25(2):158-68. 
30. Huang WY, Singer DE, Wu YL, Chiang CE, Weng HH, Lee $M$, et al. Association of Intracranial Hemorrhage Risk with non-Vitamin K Antagonist Oral Anticoagulant use vs aspirin use: a systematic review and Metaanalysis. JAMA Neurol. 2018:75(12):1511-8.

31. Sagris D, Leventis I, Georgiopoulos G, Korompoki E, Makaritsis K, Vemmos K, et al. Bleeding risk comparison between direct oral anticoagulants at doses approved for atrial fibrillation and aspirin: systematic review, meta-analysis and meta-regression. Eur J Internal Med. 2020;79:31-6.

32. Hindricks $G$, Potpara T, Dagres N, Arbelo E, Bax JJ, Blomstrom-Lundqvist C, et al. 2020 ESC Guidelines for the diagnosis and management of atrial fibrillation developed in collaboration with the European Association for Cardio-Thoracic Surgery (EACTS): The Task Force for the diagnosis and management of atrial fibrillation of the European Society of Cardiology (ESC) Developed with the special contribution of the European Heart Rhythm Association (EHRA) of the ESC. Eur Heart J. 2021:42((5):373-498.

33. January CT, Wann LS, Calkins H, Chen LY, Cigarroa JE, Cleveland JC Jr, et al. 2019 AHA/ACC/HRS focused update of the 2014 AHA/ACC/HRS guideline for the Management of Patients with Atrial Fibrillation: a report of the American College of Cardiology/American Heart Association task force on clinical practice guidelines and the Heart Rhythm Society in collaboration with the Society of Thoracic Surgeons. Circulation. 2019;140(2):e125-e51.

34. Valgimigli M, Bueno H, Byrne RA, Collet JP, Costa F, Jeppsson A, et al. 2017 ESC focused update on dual antiplatelet therapy in coronary artery disease developed in collaboration with EACTS: the task force for dual antiplatelet therapy in coronary artery disease of the European Society of Cardiology (ESC) and of the European Association for Cardio-Thoracic Surgery (EACTS). Eur Heart J. 2018;39(3):213-60.

\section{Publisher's Note}

Springer Nature remains neutral with regard to jurisdictional claims in published maps and institutional affiliations.

Ready to submit your research? Choose BMC and benefit from:

- fast, convenient online submission

- thorough peer review by experienced researchers in your field

- rapid publication on acceptance

- support for research data, including large and complex data types

- gold Open Access which fosters wider collaboration and increased citations

- maximum visibility for your research: over $100 \mathrm{M}$ website views per year

At $\mathrm{BMC}$, research is always in progress.

Learn more biomedcentral.com/submissions 